\title{
The Brazilian Amazon Protected Area Network was largely unaffected by recent satellite- detectable fires
}

Daniel P. Bebber*

*Department of Biosciences, University of Exeter, Exeter EX4 4QD, UK. Tel. +44 1392725851.

Email d.bebber@exeter.ac.uk

ORCID 0000-0003-4440-1482

Keywords: Forest fire, Brazil, Amazon, Protected Areas, Deforestation

$\underline{\text { Abstract }}$

August 2019 saw dramatic increases in wildfires in the Brazilian Amazon, leading to arguments between Brazil and G7 leaders and widespread concern among conservationists. Popular media reports suggested that 'swathes of the Amazon rainforest in Brazil are on fire'. Here we investigate the spatial distribution of fires through August 2019, showing that fires were largely restricted to deforested regions and areas with low canopy cover, particularly in unprotected areas that comprise half the region. In contrast, Brazil's protected areas had one third as many fires, and forest in protected areas with high canopy cover was almost entirely unaffected by fire. Protected areas reduce deforestation and carbon emissions, and have proved largely untouched by recent fires. However, fires in closed-canopy forest cannot readily be detected by satellite remote-sensing and so this analysis likely underestimates the burned area in intact forest, both in protected and unprotected areas.

\section{$\underline{\text { Main text }}$}

Recent wildfires in the Amazon basin have caused widespread concern from conservationists, and have triggered arguments between the government of Brazil and G7 nations regarding responsibility for the protection of Brazil's rainforests (1). The Brazilian Amazon is the world's largest intact tropical forest, estimated to hold around $50 \mathrm{Gt}$ of carbon in above-ground biomass (2). Deforestation rates in the Brazilian Amazon have varied widely over recent years with forest fires mainly affecting disturbed and logged areas (3), though droughts are becoming a greater trigger for fires (4). Fires are particularly severe during drought years which are often triggered by the El Nino Southern Oscillation (3-5). Low-intensity understorey fires under the canopy can lead to positive feedbacks, with more open canopy allowing dead trees to dry rapidly and fueling hotter and hotter burns (6). Preventing the establishment of such positive feedback loops is key to protecting remaining forest (3). Brazil has established numerous protected areas (PA) of different types and classifications, which form part of the world's protected area network that covers around $15 \%$ of the land surface (7). Deforestation rates are significantly lower within PAs than without (8), and tropical PAs are estimated to have 
reduced deforestation carbon emissions by one third in the first decade of the $21^{\text {st }}$ Century (7). Here we analyse the distribution of recent fires in the Amazon Basin to determine whether PAs have prevented forests from burning.

PAs cover approximately 45 per cent of the land surface of the Brazilian Amazon basin, with coverage scattered widely across the region (Fig. 1A). The southern border of the Brazilian Amazon is largely unprotected, however. Three quarters of the 645 PAs covering the basin are smaller than $4000 \mathrm{~km}^{2}$, while the largest at $96,500 \mathrm{~km}^{2}$ is the Yanomami Indigenous Area bordering Venezuela. PAs are highly forested, with $87 \%$ of the area having a canopy coverage of over $90 \%$ in 2018 at $0.01^{\circ}$ spatial resolution (Fig. 1B). In contrast, only $46 \%$ of unprotected areas have canopy cover over $90 \%$ in 2018. Forest area loss was 38,814 $\mathrm{km}^{2}$ from 2000 to 2018 in PAs, compared with 306,394 $\mathrm{km}^{2}$ in unprotected areas, mostly along the 'Arc of Deforestation' along the south eastern border of the Amazon Basin (Fig. 1C). Forest area loss within PAs was greatest in the Triunfo do Xingu Environmental Protection Area in Pará (5652 $\mathrm{km}^{2}$ deforested), the Parque do Xingu Indigenous Area in Mato Grosso (2609 $\mathrm{km}^{2}$ deforested), and the Jamanxim National Forest in Pará $\left(1551 \mathrm{~km}^{2}\right.$ deforested).

A record number of fires have been reported in the Brazilian Amazon in 2019, peaking in the middle of August(1). During August, fires were detected in a total of $18,005 \mathrm{~km}^{2}$ of PA forest and 58,954 $\mathrm{km}^{2}$ of unprotected forest, comprising $1.12 \%$ and $3.19 \%$ of the total PA and unprotected areas, respectively (Fig. 1D). The probability of fire detection varied with canopy cover in PA and unprotected areas (Fig. 2A). Assuming that areas deforested between 2000 and 2018 were effectively deforested (i.e. ignoring post-logging canopy recovery), in PAs the fraction of area with fires was greatest for mean canopy cover of between 20 and $30 \%$, while areas with more than $90 \%$ canopy cover remained almost entirely unburned. In unprotected areas, the fraction of areas with fires was greatest for mean canopy cover between 60 and $70 \%$, again declining to near zero for forests with more than $90 \%$ canopy cover. The fraction of area with fires increased with deforestation from 20002018 in both PAs and unprotected areas (Fig. 2B). While overall the burned area was more than three times greater in unprotected areas than in PAs, the fraction of burned area increased more rapidly with deforestation in PAs than in unprotected areas.

Fires were highly aggregated, occurring primarily in Pará (27,412 km²), Amazonas (15,074 km²), Mato Grosso $\left(14,638 \mathrm{~km}^{2}\right)$ and Rondônia $\left(11,611 \mathrm{~km}^{2}\right)$. Triunfo do Xingu Environmental Protection Area had the largest burned area $\left(3676 \mathrm{~km}^{2}\right.$ of a total area of $\left.16,784 \mathrm{~km}^{2}\right)$, comprising $20 \%$ of all the burned area within PAs. Within Triunfo do Xingu, burned areas had lower canopy cover (interquartile range $18.5-73.8 \%$ ) than unburned areas (interquartile range $40.2-98.0 \%$ ), and much greater levels of deforestation between 2000 and 2018 (interquartile range $0.23-0.81$ vs. $0.00-0.54$ ). Triunfo do 
Xingu was designated as a reserve in 2006, but between 2000 and 2018 mean forest cover fell from $96 \%$ to $64 \%$. The reasons for this rapid rate of forest loss are unclear, but appear to be driven by illegal logging and cattle ranching (9). The small town of São Félix do Xingu (population approximate 45,000) lies on the south-eastern border of the reserve, across the Xingu River. Optical remote sensing images (Google maps) show large areas of agricultural land within the reserve, and so it appears that deforestation and forest fragmentation has permitted widespread fire. Other reserves with large burned areas include Jamanxim National Forest, Pará (1230 km² burned), Jaci-Paraná, Roraima (1008 km²), Parabubure, Mato Grosso $\left(915 \mathrm{~km}^{2}\right)$ and Kayapó, Pará $\left(739 \mathrm{~km}^{2}\right)$.

There has been justifiable concern in the press and among politicians by the large areas of fire in the Brazilian Amazon during August 2019. Amazonian deforestation and fire emit around $0.2 \mathrm{Gt} \mathrm{C}$ per year (4), and threaten irreplaceable biodiversity (10). However, this analysis shows that the majority of satellite-detectable fires have occurred in unprotected areas, and that Brazil's protected area network appears robust to fire outbreaks, particularly intact forest with high canopy cover and low rates of recent deforestation. Intact, undisturbed primary forests have lower fuel loads, higher relative humidity, lower maximum temperatures and lower vapour pressure deficit than secondary forests (11), and the clear conservation of canopy cover seen across most of Brazil's protected area network is likely to have reduced fire frequency. Understorey fires under closed canopy, that are not detected directly by satellite sensors like MODIS and VIIRS (12), can lead to a positive feedback fire cycle with increasing burn intensity and canopy loss (6). The low rate of canopy loss in protected areas from 2000-2018 gives some hope that such positive feedbacks are not widespread within these undisturbed forests. While some reserves, like Triunfo do Xingu, have become highly degraded and vulnerable to burning in recent years, the recent fires show that protected area networks remain vital to reducing deforestation and fire in tropical forests.

\section{$\underline{\text { Methods }}$}

We obtained forest canopy estimates for the year 2000 and year of deforestation (2000 to 2018) at $0.0025^{\circ}$ (approximately $30 \mathrm{~m}$ ) resolution from the Global Forest Change database (13), available from http://earthenginepartners.appspot.com/science-2013-global-forest. We aggregated forest cover and deforestation data to $0.01^{\circ}$ (approximately $1.2 \mathrm{~km}$ ) resolution for computational efficiency and to match fire data resolution (see below). Forest cover in 2018 was estimated from the total deforestation fraction from 2000 to 2018, aggregated to $0.01^{\circ}$. The region of interest was the Brazilian Amazon Basin, defined by area of intersection of the Brazilian border (GIS polygon obtained from https://gadm.org) and the Amazon Basin (14) available from https://doi.org/10.3334/ORNLDAAC/1086. Forest and fire data were clipped to this region for analysis. We obtained protected area (PA) data from the WDPA (https://www.protectedplanet.net/), 
which has been used in previous analyses of the role of PAs in reducing deforestation carbon emissions (7). The GIS polygons for PAs were clipped to the Brazilian Amazon and only PAs in this region were considered in the analysis. The unprotected area was defined as the region within the Brazilian Amazon but not within a PA. We obtained fire observations from the MODIS and VIIRS systems for August $1^{\text {st }}$ to August $30^{\text {th }} 2019$ from https://earthdata.nasa.gov/earth-observationdata/near-real-time/firms/active-fire-data. MODIS fire observations are given at $1 \mathrm{~km}$ resolution and VIIRS observations at $375 \mathrm{~m}$ resolution. The area burning within a pixel is not estimated, therefore fire observations were aggregated to $0.01^{\circ}$ pixel resolution with any fire observation indicating a 'burned' pixel. Therefore, values for areas with fires are upper limits to the burned area, because actual fires may be smaller than the $0.01^{\circ}$ pixel. All analyses were conducted in R version 3.6.1. GIS operations (e.g. aggregation of gridded data, intersection of polygons) were conducted using package raster version 3.0-2.

\section{$\underline{\text { References }}$}

1. R. de O. Andrade, Alarming surge in Amazon fires prompts global outcry. Nature (2019) https:/doi.org/10.1038/d41586-019-02537-0 (September 11, 2019).

2. E. M. Nogueira, P. M. Fearnside, B. W. Nelson, R. I. Barbosa, E. W. H. Keizer, Estimates of forest biomass in the Brazilian Amazon: New allometric equations and adjustments to biomass from wood-volume inventories. For. Ecol. Manag. 256, 1853-1867 (2008).

3. M. A. Cochrane, W. F. Laurance, Synergisms among Fire, Land Use, and Climate Change in the Amazon. Ambio 37, 522-527 (2008).

4. L. E. O. C. Aragão, et al., 21st Century drought-related fires counteract the decline of Amazon deforestation carbon emissions. Nat. Commun. 9, 1-12 (2018).

5. K. Withey, et al., Quantifying immediate carbon emissions from El Niño-mediated wildfires in humid tropical forests. Philos. Trans. R. Soc. B Biol. Sci. 373, 20170312 (2018).

6. M. A. Cochrane, et al., Positive Feedbacks in the Fire Dynamic of Closed Canopy Tropical Forests. Science 284, 1832-1835 (1999).

7. D. P. Bebber, N. Butt, Tropical protected areas reduced deforestation carbon emissions by one third from 2000-2012. Sci. Rep. 7, 1-7 (2017).

8. M. Heino, et al., Forest Loss in Protected Areas and Intact Forest Landscapes: A Global Analysis. PLOS ONE 10, e0138918 (2015).

9. A. L. S. da Costa, "Efetividade de gestão da área de proteção ambiental Triunfo do Xingu: desafios de consolidação de uma unidade de conservação na região da Terra do Meio, estado do Pará,” Universidade Federal do Pará. (2013) (September 10, 2019).

10. W. F. Laurance, H. L. Vasconcelos, T. E. Lovejoy, Forest loss and fragmentation in the Amazon: implications for wildlife conservation. Oryx 34, 39-45 (2000).

11. C. Uhl, J. B. Kauffman, Deforestation, Fire Susceptibility, and Potential Tree Responses to Fire in the Eastern Amazon. Ecology 71, 437-449 (1990). 
12. D. C. Morton, et al., Mapping canopy damage from understory fires in Amazon forests using annual time series of Landsat and MODIS data. Remote Sens. Environ. 115, 1706-1720 (2011).

13. M. C. Hansen, et al., High-Resolution Global Maps of 21st-Century Forest Cover Change. Science 342, 850-853 (2013).

14. E. Mayorga, M. G. Logsdon, M. V. R. Ballester, J. E. Richey, LBA-ECO CD-06 Amazon River Basin Land and Stream Drainage Direction Maps. 318.801127 MB (2012).

Figure captions

Fig. 1. A. Brazilian Amazon with PA (green) and unprotected areas (blue). B. Forest canopy cover in 2018 (\%) in PA (green) and unprotected areas (green). C. Deforestation fraction 2000-2018 in PA (magenta) and unprotected areas (brown). D. Fire incidence area fraction in August 2019 in PA (purple) and unprotected areas (red). The Triunfo do Xingu Environmental Protection Area is outlined in black (see text). Map data were aggregated from $0.01^{\circ}$ to $0.1^{\circ}$ resolution for plotting.

Fig. 2. A. Fraction of area with fires by canopy cover class in PA (purple) and unprotected areas (red). B. Fraction of area with fires by deforestated fraction for PA (purple) and unprotected areas (red). 
